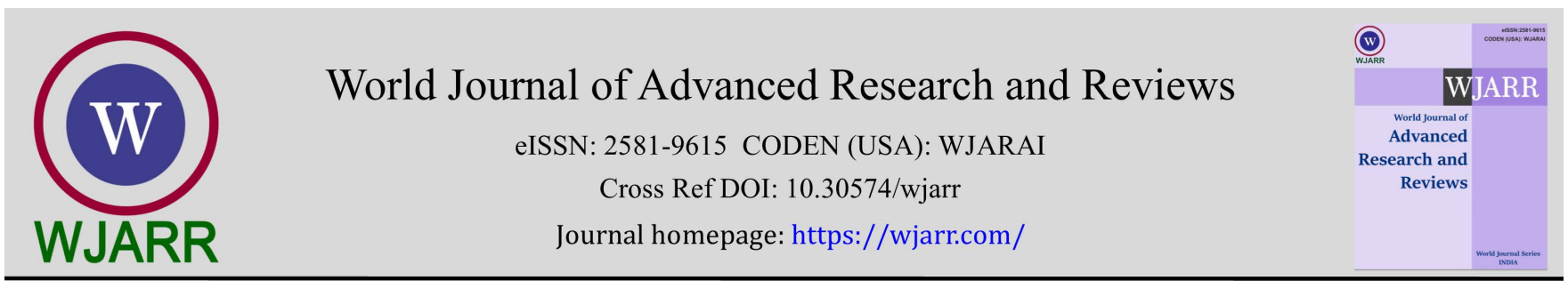

(RESEARCH ARTiClE)

\title{
Prevalence of HIV in surgical patients at the Rivers State University Teaching Hospital
}

\author{
Eli S ${ }^{1}$, Aaron FE ${ }^{2}$, Okagua $\mathrm{KE}^{3,}{ }^{*}$, Omodu $\mathrm{OJ}^{2}$ and Iyama $\mathrm{AC}^{2}$ \\ ${ }^{1}$ Mother and Baby Care Global Foundation, Nigeria. \\ 2 Department of Surgery, Rivers State University, Nigeria. \\ ${ }^{3}$ Department of Obstetrics and Gynaecology, Rivers State University Teaching Hospital, Nigeria.
}

World Journal of Advanced Research and Reviews, 2021, 11(03), 115-119

Publication history: Received on 28 June 2021; revised on 15 August 2021; accepted on 17 August 2021

Article DOI: https://doi.org/10.30574/wjarr.2021.11.3.0358

\begin{abstract}
Background: With the high prevalence of HIV in Sub-Saharan Africa, screening for this viral infection is a routine in many health institutions prior to surgery, the world has recorded success story in the research of HIV especially with the advent of Highly Active Anti-Retroviral Therapy (HAART) this disease burden has been reduced globally. The prevalence of HIV in Nigeria is $1.4 \%$.
\end{abstract}

Aim: To determine the prevalence of HIV in surgical patients at the Rivers State University Teaching Hospital (RSUTH), Port Harcourt, Rivers State, Nigeria.

Method: This was a cross sectional study of ANC attendees and surgical patients at the RSUTH, from January $1^{\text {st }}$ to June 31 st, 2019. They were surgical patients who were systematically selected, information was obtained from patients case notes with a structured proforma. The information obtained was coded and analyzed using SPSS version 25.

Result: A total of 370 patients were attended to pre-operatively. There were 146 (39.5\%) males and 224 (60.5\%) females. The mean age was 31 years. One hundred and ninety four (52.4\%) were obstetrics and gynaecological surgeries while 176 (47.6\%) were non-gynaecological surgeries. The commonest indication for surgery was caesarean representing 126 (34.1\%) of the subjects.The prevalence of HIV in surgical patients was 8 (2.1\%). Three (1.6\%) of the obstetrics and gynaecological patients had HIV compared to $1(0.5 \%)$ non-obstetrics and gynaecological patient.

Conclusion: The study revealed that prevalence of HIV in surgical patients at the RSUTH was high (2.1\%). HIV infection was thrice as common in obstetrics and gynaecological patients compared with other surgical disciplines. There is need to step up surveillance amongst ANC attendees who are reflection of the populace in this region.

Keywords: Prevalence; HIV; Surgical; Patients; RSUTH

\section{Introduction}

Human Immunodeficiency Virus (HIV) is a devastating and major public health challenge globally. ${ }^{1}$ With the high prevalence of HIV in Sub-Saharan Africa, screening for this viral infection is a routine in many health institutions prior to surger [1,2]. The world has recorded success story in the research of HIV especially with the advent of Highly Active Anti-Retroviral Therapy (HAART) in the treatment of this disease globally [1].

${ }^{*}$ Corresponding author: Okagua KE

Department of Obstetrics and Gynaecology, Rivers State University Teaching Hospital, Nigeria.

Copyright (C) 2021 Author(s) retain the copyright of this article. This article is published under the terms of the Creative Commons Attribution Liscense 4.0. 
Taking into consideration that HIV infections could be transmitted during surgical procedures makes it more worrisome to surgeons [2-5]. for this reason, preventive measures should be taken by surgeons before, during and after surgery due to the fact HIV infection is a blood borne infection [6-10].

According the World Health Organization (WHO) report for 2020 an estimate of 37.7 million [30.2-45.1 million]. people living with HIV at the end of 2020 [1]. In 2020 the recorded mortality from HIV-related causes was 680,000 and 1.5 million people contacted the disease. We all need to redouble our effort to reach the proposed global target of 95-95-95 recommended by UNAIDS, especially with respect to the excess of one million deaths recorded in Africa [6]. In addition, with the outbreak of covid-19 pandemic [3-6]. HIV preventive services has been disrupted leading to increasing number of HIV infections [4-10]. African and South-East Asian countries have greatest burden of HIV [8]. The estimate from Africa is over 30 million [7-8]. Furthermore, in African countries there is variation of the prevalence ofHIV infections with a prevalence of $1.4 \%$ from Nigeria [8]. It is however worrisome because in the globe $70 \%$ of persons living with HIV are resident in Sub-Sahara Africa $[3,47,8]$. From the inception of the disease condition HIV has claimed 36.6 million lives so far [1,2]. At present there is no established cure for HIV, however anti-retroviral drugs can control the disease [1]. In contrast to the previous statement, with available access to effective HIV prevention modalities, diagnostic tools, treatment and care, including opportunistic infections [1,4]. People living with HIV can be managed and can lead long and healthy lives $[1-4,11,12]$.

The chronicity of prevalence of HIV infection in surgical patients both in urban and rural Nigeria and suggestions on how to reduce this infection portrays the justification of this study.

\section{Aim}

The aim of this study was to determine the prevalence of HIV in surgical patients at the Rivers State University Teaching Hospital (RSUTH).

\section{Methods}

This was a six-month retrospective cross-sectional study, between $1^{\text {st }}$ January, 2019 to $31^{\text {st }}$ June, 2019 of surgical patients at the Rivers State University Teaching Hospital, Rivers State, Nigeria. Laboratory records of al serological testing on all patients for HIV performed at the haematology department of the RSUTH.

HIV serological test results for surgical patients were extracted from laboratory records of subjects were noted. Their age distributions were also extracted. In addition, other information from subjects such as their parity, educational status and gestational ages were extracted.

Serological tests for antibodies to HIV 1 and 2 were performed on serum samples obtained from subjects in line with the serial testing algorithm using determine lat (Alere). These were all done according to manufacturer's instructions. There were no direct contacts with patients. Their information gotten were coded and analysed using descriptive statistics in the form of standard deviation, frequency and proportion was performed using independent, chi square test and fishers' exact tests as appropriate. Significance level was set at 0.05 .

\subsection{Sample size estimation}

The sample size of 370 was calculated using the Kish Leslie formula for cross-sectional studies calculated, based on 1.4 $\%$ prevalence of HIV infection report by UNAIDS 2019, Nigeria [8]. at a confidence level of $95 \%$.

$$
\mathrm{n}=\mathrm{Z}^{2} \mathrm{Pq} / \mathrm{d}^{2}
$$

Were

$\mathrm{n}$ is the desired sample size

$\mathrm{Z}$ is the standard normal deviate usually set at 1.96 , which corresponds to the confidence interval

$\mathrm{P}$ is the prevalence of HIV infection which in this case is $1.4 \%$

$\mathrm{q}$ is complementary proportion equivalent to one (1), that is $1-0.14 \%$ equal to $0.86 \%$

$\mathrm{d}$ is the degree of accuracy desired which is $5.0 \%(0.05 \%)$

$$
n=1.96^{2} \times 0.14(1-0.14) / 0.05^{2}
$$


$=372$, this was rounded up to 370

\subsection{Study Population}

This study was conducted in the Rivers State University Teaching Hospital. It is a 370-bed hospital located at Harley Street Port Harcourt Local Government Area of Rivers State, South-South Nigeria. It is a tertiary health institution that provides all levels of health care services to Rivers, Bayelsa, Delta, Imo, Abia and Akwa-Ibom States. The Obstetrics/Gynaecology and surgical department are two of the clinical departments of the hospital with twelve (13) and twelve (12) Consultant Staff respectively.

\section{Results}

A total of 370 patients were attended to pre-operatively. There were $146(39.5 \%)$ males and 224 (60.5\%) females. The mean age was 31 years. One hundred and ninety-four (52.4\%) were obstetrics and gynaecological surgeries while 176 $(47.6 \%)$ were non-gynaecological surgeries. The commonest indication for surgery was caesarean representing 126 $(34.1 \%)$ of the subjects. The prevalence of HIV in surgical patients was $8(2.1 \%)$. Three $(1.6 \%)$ of the obstetrics and gynaecological patients had HIV compared to $1(0.5 \%)$ non-obstetrics and gynaecological patient. For the educational status 17 (4.6\%) had primary level of education, 222 (60\%) had secondary education, 121 (32.7\%) had tertiary education and $10(2.7 \%)$ had no formal education.

Table 1 Sex distribution of subjects in the study

\begin{tabular}{|l|c|c|}
\hline Sex & Frequency & Percentage (\%) \\
\hline Male & 146 & 39.5 \\
\hline Female & 224 & 60.5 \\
\hline & 370 & 100 \\
\hline
\end{tabular}

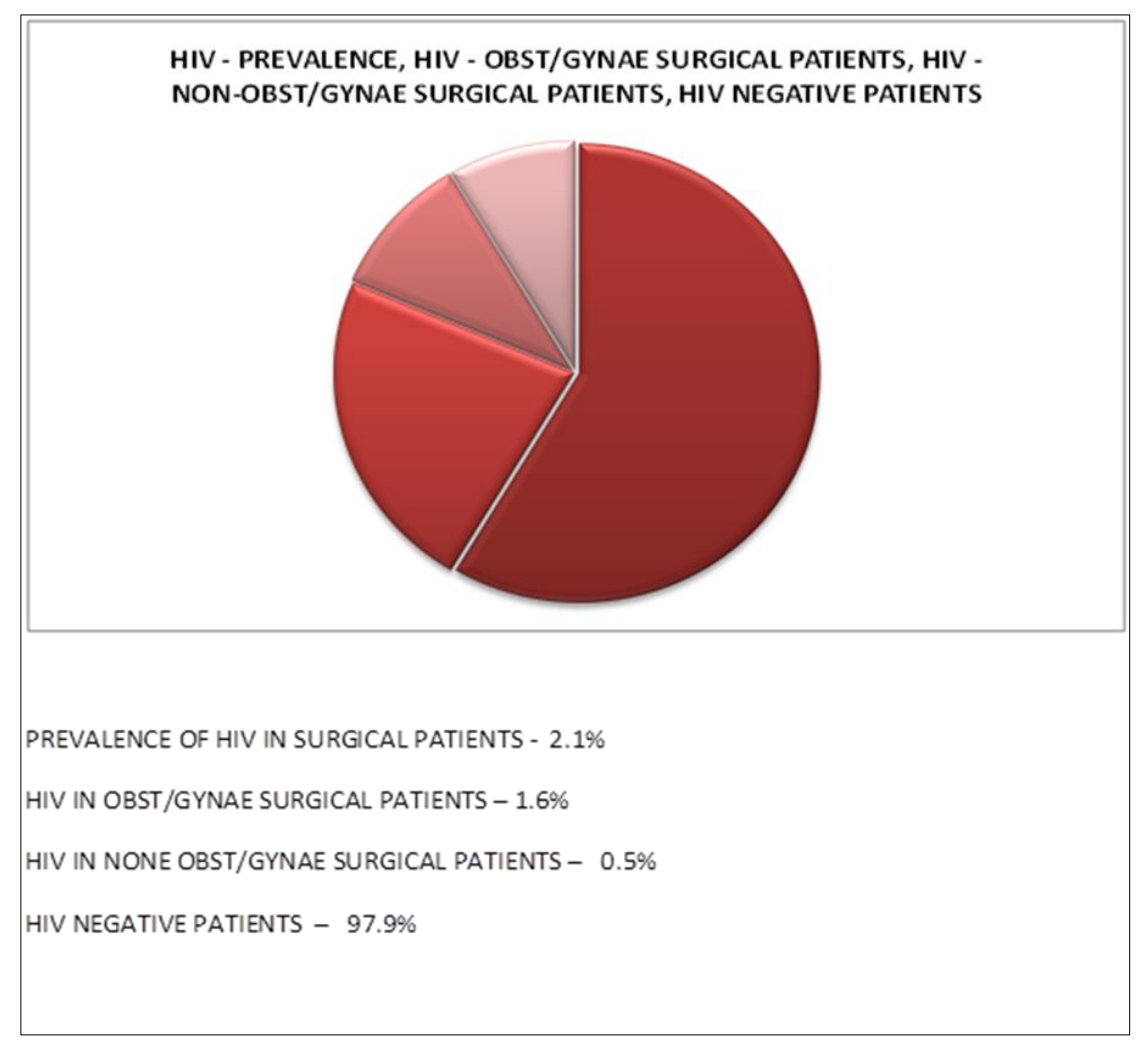

Figure 1 Prevalence of HIV infections 
Table 2 Distribution of Surgeries

\begin{tabular}{|l|l|l|}
\hline Surgeries & Frequency & Percentage (\%) \\
\hline Obstetrics/gynaecological surgeries & 194 & 52.6 \\
\hline Non-obstetrics/gynaecological surgeries & 176 & 47.4 \\
\hline
\end{tabular}

Table 3 HIV and NON-HIV infected surgical patients at RSUTH

\begin{tabular}{|l|c|c|}
\hline & Number & Percentage frequency \\
\hline HIV & 8 & $2.1 \%$ \\
\hline NON-HIV & 362 & $97.9 \%$ \\
\hline
\end{tabular}

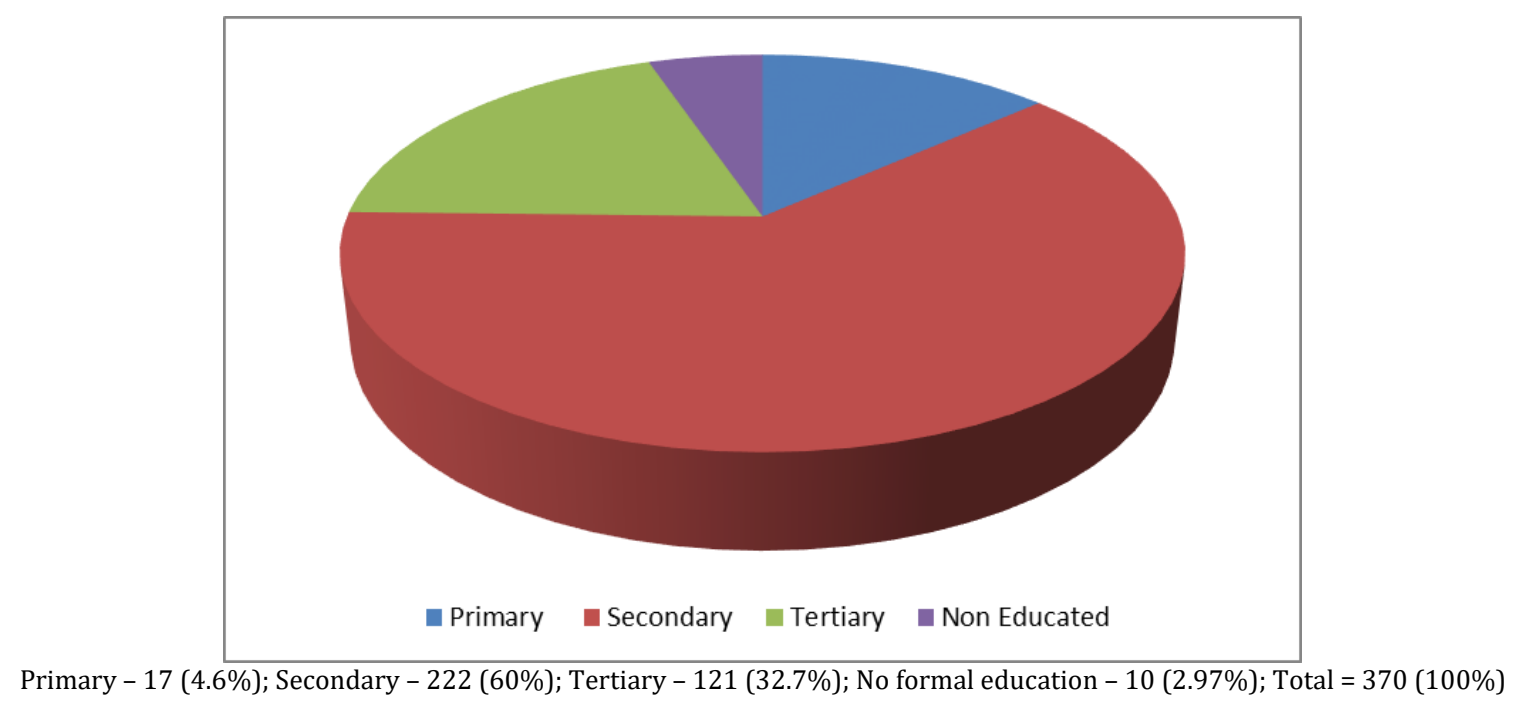

Figure 2 Distribution of educational status of the subjects

\section{Discussion}

The study revealed the prevalence of HIV in surgical patients at the Rivers State University Teaching Hospital as $2.1 \%$ as shown in table 3 and figure 1 respectively. The prevalence of HIV amongst obstetrics and gynaecological patients who had surgery was $1.6 \%$, while for the non-obstetrics and gynaecological surgical patients the HIV prevalence was $0.5 \%$ respectively this is shown in figure 1 . From UNAIDS report the prevalence of HIV in Nigeria is 1.4\%, [8]. this means obstetrics and gynaecological surgical patients had higher prevalence of HIV at $1.6 \%$ while non-obstetrics and gynaecological surgical patients had a lower HIV prevalence when compared to the national figure of $1.4 \%$. [6-8]. In a study conducted by Ozim et the prevalence of HIV among pregnant women in Nigeria was $7.22 \%$ [7]. This figure was higher than that of our study of 1.6\%. There could have been some reasons for this difference in the prevalence. One of such reasons could be due to the fact that our case was a subset of all the antenatal mothers undergoing surgery which not be as many as all the ante natal mothers screened for HIV. Another reason may be due to the larger sample size of the study done by Ozim et al when compared to our study which was a hospital-based study.

When compared to previous years, the prevalence of HIV in Nigeria is lower [9]. This is as a result of better health awareness in urban, our study was conducted in the teaching hospital in Port Harcourt, Nigeria [9]. In addition, access to internet facilities and health enlightenment progammes by government and non-government agencies have gained more grounds in the prevention of HIV when compared to the past [9-10]. Further more with the advent of antiretroviral therapy viral load of the disease have been controlled on those affected and transmission rate reduced amongst the populace [9-12]. 
Scholars have also noted that subsidized or free screening of HIV in the recent past especially in the urban areas by donor agencies and free medicals outreach are common have contributed in curtailing the spread of HIV.

\section{Conclusion}

The prevalence of HIV infection in surgical patients at the Rivers State University Teaching Hospital was $2.1 \%$. The prevalence was approximately 3 times higher in obstetrics and gynaecological surgical patients when compared to nonobstetrics and gynaecological surgical patients. Over the years the prevalence of HIV has been on the decline globally and also in Sub-Saharan Africa that bears the burden of HIV/AIDS. With the emergency of covid-19 pandemic with distraction in the attention given to proposal 95-95-95 by UNAIDS the world needs to remain focused in curtailing the spread of HIV especially by employing screening tools prior to surgical procedures together with the use of antiretroviral drugs keeping in view the discovery of HIV vaccines.

\section{Compliance with ethical standards}

\section{Acknowledgments}

Mother, Baby and Adolescent Care Global Foundation.

\section{Disclosure of conflict of interest}

There was no conflict of interest by contributing authors.

\section{Statement of informed consent}

It was a retrospective study.

\section{References}

[1] Gonzalez-Alcaide G, Menchi-Elani M. HIV/AIDS research in Africa and the Middle East: participation and equity in north-south collaborations and relationships. Global Health. 2020; 16: 83.

[2] Michael AH, Leo BH, Daniel BK. Surgical Outcomes in Immunodeficiency Virus-Infected Patients in the Era of Highly Active Antiretroviral Therapy. Arch Surg. 2006; 141(12): 1238-1245.

[3] Runodada PM, Muguti GI. Surgical outcomes in HIV positive patients following major surgery at two tertiary institutions in Harare, Zimbabwe. International Journal of Surgery. 2020; 22: 12-17.

[4] Owotade FJ, Ogunbodede EO, Sowande OA. HIV/AIDS pandemic and surgical practice in a Nigerian teaching hospital. Trop. Doct. 2003; 33(4): 228-31.

[5] Ssentongo P, Heilbrum ES, Ssentongo AE et al. Epidemiology and outcomes of COVID-19 in HIV-infected individuals: a systemic review and meta-analysis. Sci Rep. 2021; 11: 6283.

[6] Omotola CA et al. Co-infection of Human Immunodeficiency Virus Infected Patients with Hepatitis B Virus in Lokoja, North Central Nigeria. Viral Immunol. 2020; 33(5): 391-395.

[7] Ozim C, Mahendran R, Amalan M, Puthussery S. Immunodeficiency Virus among pregnant women in Nigeria. European Journal of Public Health. 2020; 30: s5.

[8] New survey results indicate that Nigeria has an HIV prevalence of $1.4 \%$ UNAIDS. Https://www.unaids.org $>$ march>2019 (accessed 13/9/2021)

[9] Van Schalwyk C. Modelling of HIV prevention and treatment progress in five South African metropolitan districts. Scientific Reports. 2021; 11: 5652.

[10] Dwyer-Lindgren, L et al. Mapping HIV prevalence in sub-Saharan Africa between 2000 and 2017. Nature. 2019; 570: 189-193.

[11] McGilen JB, Anderson SJ, Dybul MR, Hallett TB. Optimum resource allocation to reduce HIV incidence across subSaharan Africa: a mathematical modeling study. Lancet HIV. 2016;3:e441-e448.

[12] Dyson T. HIV/AIDS and urbanization. Popul. Dev Rev. 2003; 29: 427-442. 